\title{
Pressure controlled- inverse ratio ventilation and pulmonary gas exchange during lower abdominal surgery
}

W.A. Tweed MD FRCPC, P.L. Tan MBBS MMed(Annesch) has been used successfully in the treatment of respiratory failure, it has not been applied to the treatment of respiratory dysfunction during anaesthesia. With PC-IRV the inspiratory wave form is fundamentally altered so that inspiratory time is prolonged (inverse l:E), inspiratory flow rate is low, and the peak inspiratory pressure is limited. Positive end-expiratory pressure (PEEP) can be applied and the mean airway pressure is higher than with conventional ventilation. To assess the clinical efficacy of this new mode of ventilation we studied ten patients having lower abdominal gynaecologic surgery in the Trendelenburg position under general anaesthesia. Pulmonary $\mathrm{O}_{2}$ exchange was determined during four steady states: awake control (AC), after 30 and 60 min of PC.IRV during surgery, and at the end of surgery. Patients' lungs were ventilated with air $\mathrm{O}_{2}$ by a Siemens $900 \mathrm{C}$ servo ventilator in the PC-IRV mode with an I: $E$ ratio of 2:I and $5 \mathrm{~cm} \mathrm{H} \mathrm{H}_{2} \mathrm{O}$ of $\mathrm{PEEP}$. The $\mathrm{FlO}_{2}$ was controlled at 0.5 and arterial blood gases were used to calculate the oxygen tension-based indices of gas exchange. There were significant increases of $(A-a) \mathrm{DO}_{2}$ at 30 and $60 \mathrm{~min}(41$ and $43 \%$ ). These changes were less than those reported in a previous study using

\section{Key words}

LUNG: gas exchange, shunting;

VENTLATION: artificial, tidal volume, oxygen tension (gradients), inverse ratio, pressure controlled; OXYGEN: blood levels, gradients, tension.

From the Department of Anaesthesia, National University Hospital, National University of Singapore, Lower Kent Ridge Road, Singapore 0511.

Address correspondence to: Dr. W.A. Tweed, Department of Anaesthesia, Health Sciences Centre, Room LB-315, 60 Pearl St., Winnipeg, MB, Canada R3E 1X2.

Accepted for publication 4ih August, 1992. conventional tidal volume ventilation $\left(7.5 \mathrm{ml} \cdot \mathrm{kg}^{-i}\right)$ and were similar to those in patients whose lungs were ventilated with high tidal volumes $\left(12.7 \mathrm{ml} \cdot \mathrm{kg}^{-1}\right)$. Thus, in this clinical model of compromised gas exchange, arterialoxygenation was better with $P C-I R V$ than with conventional ventilation, but not better than with large tidal volume ventilation.

Bien que la ventilation à pression contrôlée avec rapport $U E$ inversé (PC-IRV) ait été utilisée avec succès pour traiter l'insuffisance respiratoire, on ne l'a pas appliquée jusqu'd maintenant au traitement du dysfonctionnement respiratoire peropératoire. Sous ce mode de ventilation, la courbe d'insufflation inspiratoire est altérée de sorte que la durée de la phase inspiratoire est prolongée (rapport $1 / E$ inversé), le débit inspiratoire est maintenu bas, et le pic inspiratoire est plafonné. Une pression positive expiratoire (PEP) peut être ajoutée. Sur les voies aériennes, la pression moyenne devient plus élevée qu'avec la ventilation conventionnelle. Pour évaluer l'efficacité de ce nouveau mode de ventilation sous anesthésie générale, nous avons étudié dix patientes subissant une chirurgie gynécologique en position de Trendelembourg. Pour l'oxygène, les échanges pulmonaires sont évalués à l'état d'équilibre a quatre moments : contrôle à l'état d'éveil, après 30 et $60 \mathrm{~min}$ de $P C$ IRV et après la chirurgie. Les poumons sont ventilés avec un mélange air $/ \mathrm{O}_{2}$ par un ventilateur Siemens Servo $900 \mathrm{C}$ en mode IRV-PC avec un rapport $I / E$ de $2 / l$ et un $P E P$ de $5 \mathrm{~cm} \mathrm{H}_{2} \mathrm{O}$. La $\mathrm{FlO}_{2}$ est maintenue d̀ 0,5 et la mesure des échanges gazeux se fait par les gaz artériels. Nous avons trouvé une augmentation importante de la $(A-a) D_{2}$ à 30 et $60 \mathrm{~min}(4)$ et $\left.43 \%\right)$. Ces changements sont moindres que ceux qui ont été ropportés dans une étude antérieure où on utilisait le mode ventilatoire avec volumes courants usuels $\left(7,5 \mathrm{~m} \cdot \mathrm{kg}^{-1}\right)$ et étaient identiques a ceux de patients ventiles avec des volumes courants élevés ( 32.7 $\left.m l \cdot \mathrm{kg}^{-1}\right)$. Ainsi, avec ce modèle clinique présentant une situation d'échanges gazeux perturbés, les résultats de la mesure de l'oxygénation du sang artériel sont supérieurs avec $P C$-IRV que sous ventilation conventionnelle mais identiques à ceux qu'on obtient avec une ventilation à grands volumes courants. 
Pressure controlled-inverse ratio ventilation (PC-IRV) has been used in the treatment of severe respiratory failure. ${ }^{1,2}$ It permits delivery of a pre-determined tidal volume (VT) with a limited peak inspiratory pressure (PIP), high mean airway pressure (AWP), and variable positive endexpiratory pressure (PEEP), Boros ${ }^{3}$ has shown that the beneficial effect of positive pressure ventilation in neonatal repiratory failure is directly related to the level of mean AWP, and this may explain the efficacy of PC-IRV in severe respiratory failure. Some manifestations of pulmonary dysfunction during anaesthesia, such as atelectasis ${ }^{4}$ and shunting of pulmonary venous blood, ${ }^{5}$ are similar to those of respiratory failure. We therefore undertook a clinical trial, in patients known to be at high risk for pulmonary dysfunctiom, to assess the effect of PC-IRV on gas exchange during anaesthesia and surgery.

\section{Methods}

The protocol for this study was approved by Departmental and Institutional Ethics Review Committees.

The methods were similar to those reported previously. ${ }^{6}$ Subjects for this study were ten adult ASA physical status I or II females having elective intra-abdominal gynaecological surgery through lower abdominal incisions. Various degrees of intra abdominal packing, retraction, and supine Trendelenburg (head down) positioning were common to all.

Routine preanaesthetic workup included history, physical examination and chest radiograph. None was grossly obese, a cigarette smoker, or had symptomatic pulmonary disease.

A 20-gauge teflon cannula was inserted, with the patient's consent and the aid of local anaesthesia, in a radial artery. After premedication with lorazepam or midazolam, all had total intravenous general anaesthesia with tracheal intubation as previously described. ${ }^{6}$ While lying supine before induction of anaesthesia they breathed air $/ \mathrm{O}_{2}\left(\mathrm{FIO}_{2}=0.5\right)$ for five minutes from the ventilator circuit via a tight fitting mask (AC condition). After tracheal intubation and four or five manual inflations they were connected to the Siemens $900 \mathrm{C}$ servo ventilator in the PC-IRV mode with a rate of $10 \mathrm{~min}^{-1}$, an I:E ratio of 2:1 and $5 \mathrm{~cm} \mathrm{H}_{2} \mathrm{O}$ of PEEP. The fresh gas mixture was air $/ \mathrm{O}_{2}$ and the inspiratory $\mathrm{O}_{2}$ concentration $\left(\mathrm{FIO}_{2}\right)$ of 0.5 was monitored continuously by the Siemens oxygen analyzer. Tidal volume (VT) was set by adjusting peak inspiratory pressure (PIP) so that end-tidal $\left.\mathrm{CO}_{2}(\mathrm{FETCO})_{2}\right)$ was between 4.5 and $5.0 \%$ ( $\mathrm{VT}$ of $7-8 \mathrm{ml} \cdot \mathrm{kg}^{-1}$ ). During the study only the VT was adjusted to maintain near constant $\mathrm{FETCO}_{2}$.

After five minutes of $\mathrm{AC}$ breathing, at 30 and $60 \mathrm{~min}$ of anaesthesia, and during abdominal closure, an anaerobic arterial blood sample was drawn from the radial artery cannula, placed on ice, and analyzed within three minutes in a Nova Stat Profile Blood Gas Analyzer at $37^{\circ} \mathrm{C}$. The analyser was calibrated as previously described. Heart rate (HR) and blood pressure (BP) were measured by a Dinamap Automatic BP Monitor at three-minute intervals.

The calculation of alveolar oxygen tension was based on the formula adopted by Pappenheimer et al. ${ }^{7}$

$\mathrm{PAO}_{2}=\mathrm{FlO}_{2}\left(\mathrm{~PB}-\mathrm{PAH}_{2} \mathrm{O}\right)-\mathrm{PaCO}_{2}\left[\mathrm{FIO}_{2}+\left(1-\mathrm{FlO}_{2}\right) / \mathrm{RQ}\right]$

Since Singapore is at sea level the barometric pressure PB was assumed to be $760 \mathrm{mmHg}$ and alveolar water vapour partial pressure $\left(\mathrm{PAH}_{2} \mathrm{O}\right)$ to be $47 \mathrm{mmHg}$. Day to day variation in barometric pressure in Singapore is less than one percent.* If $\mathrm{FIO}_{2}$ and $\mathrm{RQ}$ are assigned constant values of 0.5 and $0.9 \dagger$ respectively the Pappenheimer formula reduces to:

$$
\mathrm{PAO}_{2}=357-\left(\mathrm{PaCO}_{2} \times 1.06\right)
$$

Pulmonary gas exchange was assessed by calculating the alveolar-arterial oxygen tension difference, (A-a) $\mathrm{DO}_{2}$, that is the calculated $\mathrm{PAO}_{2}$ minus the temperature corrected $\mathrm{PaO}_{2}$.

Because the data did not meet the requirements of normal distribution and equal variances non-parametric analysis was used. Two sample comparisons were by the Wilcoxon signed rank test for paired data and the MannWhitney $\mathbf{u}$ test for unpaired data.

\section{Results}

The demographic data are shown in Table I, PC-IRV column. These patients were similar to those of a previous study ${ }^{6}$ (Table I).

During PC-IRV average VT was $8 \mathrm{ml} \cdot \mathrm{kg}^{-1}$, PIP was 14-15 $\mathrm{cm} \mathrm{H}_{2} \mathrm{O}$ and mean AWP was $12-13 \mathrm{~cm} \mathrm{H}_{2} \mathrm{O}$. There were no differences among the four study conditions in $\mathrm{pH}, \mathrm{PAO}_{2}, \mathrm{Bp}$, or temperature, and $\mathrm{PaCO}_{2}$ remained constant during controlled ventilation (Table II).

There were increases in (A-a) $\mathrm{DO}_{2}$ at 30 and $60 \mathrm{~min}$ compared with AC $(41 \%$ and $43 \%$ respectively, $P<0.05)$. During abdominal closure, that is after removal of packs and retractors and return to the supine position, (A-a) $\mathrm{DO}_{2}$ was not different from $A C$.

These results were compared with those of a previously reported study, ${ }^{6}$ in which the lungs of similar patients had been ventilated with conventional tidal volumes (CVT, 7.5 $\mathrm{ml} \cdot \mathrm{kg}^{-1}$ ) or high tidal volumes (HVT, $12.7 \mathrm{ml} \cdot \mathrm{kg}^{-1}$ ) (Table I). The increase in $(A-a) D_{2}$ with PC-IRV was less than that during $C V T$ ventilation and similar to that found with HVT.

*Personal communication, The Meteorological Service of Singapore.

†Value obtained from previous metabolic studies during anaesthesia in this Department. 
TABLE I Pulmonary gas exchange during anaesthesia: comparison of three modes of ventilation

\begin{tabular}{|c|c|c|c|}
\hline & \multicolumn{3}{|c|}{ Ventilatory group } \\
\hline & $C V r^{6}$ & $H V_{T^{6}}$ & $P C-I R V$ \\
\hline \multicolumn{4}{|c|}{ Compararive data: mean $\pm S D$ (range) } \\
\hline$n$ & 12 & 12 & 10 \\
\hline Age yr & $\begin{array}{l}46.7 \pm 11.8 \\
(21-69)\end{array}$ & $\begin{array}{l}43.8 \pm 9.7 \\
(26-64)\end{array}$ & $\begin{array}{l}45.7 \pm 7.1 \\
(38-63)\end{array}$ \\
\hline Weight kg & $\begin{array}{l}61.3 \pm 10.4 \\
(47-84)\end{array}$ & $\begin{array}{l}59.5 \pm 10.6 \\
(43-73)\end{array}$ & $\begin{array}{l}58.1 \pm 10 \\
(47-70)\end{array}$ \\
\hline ASA V/I & $8 / 4$ & $7 / 5$ & $7 / 3$ \\
\hline Cigarette smokers & $2 / 12$ & $1 / 12$ & 0110 \\
\hline \multicolumn{4}{|c|}{ Gas exchange: mean $\pm S E M$} \\
\hline $\begin{array}{l}\mathrm{FlO}_{2} \\
\text { Awake cont. }(\mathrm{A}-\mathrm{a}) \mathrm{DO}_{2} \\
\% \text { Increase at } 30 \mathrm{~min}\end{array}$ & $\begin{array}{l}0.50 \\
82 \pm 7 \\
126 \pm 31 \%\end{array}$ & $\begin{array}{l}0.50 \\
77 \pm 10 \\
48 \pm 32 \%\end{array}$ & $\begin{array}{l}0.50 \\
65 \pm 6 \\
41 \pm 13 \% *\end{array}$ \\
\hline
\end{tabular}

${ }^{*} P<0.05$ compared with the increase during $\mathrm{CVT}$ by the Mann-Whitney u test for unpaired data.

TABLE II Pressure controlled-inverse ratio ventilation (mean \pm SEM, $n=10$ )

\begin{tabular}{|c|c|c|c|c|}
\hline & \multicolumn{4}{|c|}{ Srudy conditions } \\
\hline & $A C$ & $30 \mathrm{~min}$ & $60 \min$ & $C L$ \\
\hline \multicolumn{5}{|l|}{ Controlled variables } \\
\hline $\mathrm{VT} \mathrm{ml} \cdot \mathrm{kg}^{-1}$ & & $8.1 \pm 0.4$ & $7.7 \pm 0.4$ & $8.0 \pm 0.4$ \\
\hline $\mathrm{FiO}_{2}$ & 0.50 & 0.50 & 0.50 & 0.50 \\
\hline $\mathrm{PAO}_{2} \mathrm{mmHg}$ & $314 \pm 2$ & $319 \pm 1$ & $319 \pm 1$ & $319 \pm 1$ \\
\hline Temp ${ }^{\circ} \mathrm{C}$ & $37.0 \pm 0$ & $36.3 \pm 0.2$ & $36.2 \pm 0.2$ & $35.8 \pm 0.3$ \\
\hline \multicolumn{5}{|l|}{ Cardiovascular } \\
\hline Syst BP mmHg & $122 \pm 5$ & $111 \pm 6$ & $105 \pm 5$ & $107 \pm 4$ \\
\hline Diast $\mathrm{BP} \mathrm{mmHg}$ & $70 \pm 3$ & $64 \pm 4$ & $63 \pm 4$ & $63 \pm 3$ \\
\hline \multicolumn{5}{|l|}{ Airway Pressures } \\
\hline PIP $\mathrm{cm} \mathrm{H}_{2} \mathrm{O}$ & & $14.5 \pm 0.7$ & $14.7 \pm 0.5$ & $14.2 \pm 0.6$ \\
\hline Mean AWP cm $\mathrm{H}_{2} \mathrm{O}$ & & $12.1 \pm 0.6$ & $12.3 \pm 0.4$ & $12.1 \pm 0.5$ \\
\hline PEEP $\mathrm{cm} \mathrm{H}_{2} \mathrm{O}$ & & 5.0 & 5.0 & 5.0 \\
\hline \multicolumn{5}{|l|}{ Anterial blood gases } \\
\hline $\mathrm{pH}$ & $7.37 \pm 0.02$ & $7.40 \pm 0.01$ & $7.40 \pm 0.01$ & $7.38 \pm 0.01$ \\
\hline $\mathrm{PaCO}_{2} \mathrm{mmHg}$ & $41 \pm 2$ & $36 \pm 1^{*}$ & $36 \pm 1^{*}$ & $36 \pm 1^{*}$ \\
\hline $\mathrm{PaO}_{2} \mathrm{mmHg}$ & $249 \pm 7$ & $228 \pm 12$ & $224 \pm 11$ & $237 \pm 13$ \\
\hline Bicarb $\mathrm{mEq} \cdot \mathrm{L}^{-1}$ & $23.3 \pm 0.4$ & $23.3 \pm 0.3$ & $22.9 \pm 0.4$ & $22.2 \pm 0.4$ \\
\hline \multicolumn{5}{|c|}{ Pulmonary ventilation and gas exchange } \\
\hline$\dot{\mathrm{V}} \mathrm{ml} \cdot \mathrm{kg}^{-1} \cdot \mathrm{min}^{-1}$ & & $81 \pm 4$ & $77 \pm 4$ & $80 \pm 4$ \\
\hline$(A-a) \mathrm{DO}_{2}$ & $65 \pm 6$ & $91 \pm 12^{*}$ & $95 \pm 11^{*}$ & $82 \pm 13$ \\
\hline \% Change from $A C$ & & $41 \pm 13^{*}$ & $43 \pm 15^{*}$ & $26 \pm 13$ \\
\hline
\end{tabular}

AC - awake control; CL - abdominal closure; PIP - peak inspiratory pressure; mean AWP - Mean airway pressure; PEEP - positive end expiratory pressure.

$* P<0.05$ compared with AC by the Wilcoxon signed rank test for paired data.

\section{Discussion}

In this sample of patients there was considerable worsening of gas exchange during lower abdominal surgery, when the effects of packs, retractors and positioning were maximal. During abdominal closure, when these factors were removed, oxygenation was not different from control, suggesting that the gas exchange dysfunction was largely due to surgical and positional factors. We believe that these factors impede diaphragmatic excursion, and that this is a model of compression atelectasis with pulmonary venous shunting.

This is a descriptive study with historical controls. In 
comparison with the previous study, PC-IRV provided protection against hypoxaemia about equal to that of HVT ventilation.

We have also investigated time cycled-inverse ratio ventilation (TC-IRV), without PEEP, in a group of orthopaedic patients and found no difference between it and conventional ventilation. ${ }^{8}$ However, the orthopaedic patients were not subjected to compressive and positional forces, as were the gynaecological subjects, and therefore were not at the same risk for compression atelectasis. In addition, although both modes of ventilation increased mean AWP, there was a fundamental difference between them. With PC-IRV the increased airway pressure was sustained throughout the respiratory cycle, with TC-IRV it was not. We suggest that continuous positive airway pressure is more effective to increase resting lung volume (FRC) and improve $\dot{V}_{A} / \dot{Q}$ matching in patients with pulmonary dysfunction during anaesthesia.

Gas exchange impairment occurs during general anaesthesia in obese patients, cigarette smokers, and those with pre-existing lung disease, but only minimally in healthy young non-smokers. ${ }^{9}$ The FRC and total pulmonary compliance are reduced with onset of general anaesthesia. When FRC is reduced to below awake closing capacity (CC), Dueck et al. found physiological shunting in dependent areas of the lung. ${ }^{10}$ Hedenstierna et al. have also found venous shunting in anaesthetized patients, and have demonstrated dependent atelectasis, in both the supine and lateral positions, by CT scanning. ${ }^{11-13} \mathrm{Al}$ though we have not examined the pathophysiology of impaired gas exchange in our patients, the evidence cited above supports our contention that it can be reasonably ascribed to increased intra-abdominal pressure, cephalad shift of the diaphragm, compression atelectasis, and venous shunting. We propose that PC-IRV increases resting lung volume, that is FRC, and prevents compression atelectasis under these circumstances.

Continuous positive pressure ventilation (CPPV) and conventional ratio ventilation with PEEP have also been shown to improve oxygenation in some, but not all, studies. ${ }^{14-16}$ Thus, PC-IRV can be viewed as another form of CPPV, but with higher mean AWP and a prolonged inspiratory waveform.

The present studies show that, in patients at risk for compression atelectasis and pulmonary venous shunting, impairment of $\mathrm{O}_{2}$ exchange can be reduced by PC-IRV, which combines high mean AWP with PEEP. However, PC-IRV at the pressures and ratios that we have used does not appear to be superior to ventilation with large tidal volumes of $12-13 \mathrm{ml} \cdot \mathrm{kg}^{-1}$.

\section{Acknowledgements}

We gratefully acknowledge the support of the National University of Singapore, the National University Hospital, and Mr. Bob Mong of Siemens (Pte) Ltd., Singapore, for the loan of the ventilator.

\section{References}

1 Tharratt RS, Allen RP, Albertson ET. Pressure controlled inverse ratio ventilation in severe adult respiratory failure. Chest 1988; 94: 755-62.

2 Abraham E, Yoshihara G. Cardiorespiratory effects of pressure controlled inverse ratio ventilation in severe respiratory failure. Chest 1989; 96: 1356-9.

3 Boros $S J$. Variations in inspiratory:expiratory ratio and airway pressure wave form during mechanical ventilation: the significance of mean airway pressure. J Pediatr 1979; 94: 114-7.

4 Hedenstierna $G$. Gas exchange during anaesthesia. $\mathrm{Br} \mathrm{J}$ Anaesth 1990; 64: 507-14.

5 Price HL, Cooperman LH, Warden JC, Morris JJ, Smith TC. Pulmonary hemodynamics during general anaesthesia in man. Anesthesiology 1969; 30: 629-36.

6 Tweed WA, Phua WT, Chong KY, Lim E, Lee TL. Large tidal volume ventilation improves pulmonary gas exchange during lower abdominal surgery in Trendelenburg's position. Can J Anaesth 1991; 38: 989-95.

7 Pappenheimer JR, Comroe JH, Cournand A, et al. Standardization of definitions and symbols in respiratory physiology. Fed Proc 1950; 9: 602-5.

8 Tweed WA, Lee TL. Time-cycled inverse ratio ventilation does not improve gas exchange during anaesthesia. Can J Anaesth 1991; 38: 311-7.

9 Rehder K, Knopp TJ, Sessler AD, Didier EP. Ventilationperfusion relationships in young healthy awake and anesthetized paralyzed man. J Appl Physiol 1979; 47: 745-53.

10 Dueck R, Prutow RJ, Davies NJH, Clausen JL, Davidson $T M$. The lung volume at which shunting occurs with inhalation anaesthesia. Anesthesiology 1988; 69: 854-61.

11 Gunnarsson L, Strandberg A, Brismar B, et al. Atelectasis and gas exchange impairment during enflurane/nitrous oxide anaesthesia. Acta Anaesthesiol Scand 1989; 33: 629-37.

12 Klingstedt $C$, Hedenstierna $G$, Lundquist $H$, et al. The influence of body position and differential ventilation on lung dimensions and atalectasis formation in anaesthetized man. Acta Anaesthesiol Scand 1990; 34: 315-22.

13 Klingstedt $C$, Hedenstierna $G$, Baehrendtz $S$, et al. Ventilation-perfusion relationships and atelectasis formation in the supine and lateral positions during conventional ventilation and differential ventilation. Acta Anaesthesiol Scand 1990; 34: 421-9.

14 Wyche MQ, Teichner RL, Kallos T, Marshall BE, Smith TC. Effects of continuous positive pressure breathing on functional residual capacity and arterial oxygenation during intra-abdominal operations. Anesthesiology 1973; 38: 68-74.

15 Bindslev LG, Hedenstierna G, Santesson J, Gottlieb I, 
Carvallhas A. Ventilation-perfusion distribution during inhalation anaesthesia. Acta Anaesthesiol Scand 1981; 25: 360-71.

16 Visick WD, Fairley $H B$, Hickey RF. The effects of tidal volume and end-expiratory pressure on pulmonary gas exchange during anesthesia. Anesthesiology 1973; 39: 285-90. 